BULLETIN Bulletin hispanique

HISPANIQUE Université Michel de Montaigne Bordeaux

118-2 | 2016

Varia

\title{
Maximiliano Barrio Gozalo, La Santa Sede y los obispos españoles en el Trienio Liberal (1820-1823)
}

Rico Adrados, Burgos, 2015

Joan Pubill Brugués

\section{CpenEdition}

\section{Journals}

Edición electrónica

URL: http://journals.openedition.org/bulletinhispanique/4685

DOI: 10.4000/bulletinhispanique.4685

ISSN: 1775-3821

\section{Editor}

Presses universitaires de Bordeaux

\section{Edición impresa}

Fecha de publicación: 15 diciembre 2016

Paginación: 738-741

ISBN: 979-10-300-0125-9

ISSN: 0007-4640

Referencia electrónica

Joan Pubill Brugués, « Maximiliano Barrio Gozalo, La Santa Sede y los obispos españoles en el Trienio Liberal (1820-1823) », Bulletin hispanique [En línea], 118-2 | 2016, Publicado el 15 diciembre 2016 consultado el 23 septiembre 2020. URL : http://journals.openedition.org/bulletinhispanique/4685 ; DOI : https://doi.org/10.4000/bulletinhispanique.4685

Este documento fue generado automáticamente el 23 septiembre 2020

Tous droits réservés 


\section{Maximiliano Barrio Gozalo, La Santa Sede y los obispos españoles en el Trienio Liberal (1820-1823)}

Rico Adrados, Burgos, 2015

Joan Pubill Brugués

\section{REFERENCIA}

Maximiliano Barrio Gozalo, La Santa Sede y los obispos españoles en el Trienio Liberal (1820-1823), Publicaciones del Instituto Español de Historia Eclesiástica, n ${ }^{\circ}$ 2, Rico Adrados, Burgos, 2015, pp. 339. ISBN: 978-84-944877-3-6

1 Las explicaciones sintéticas a las que obliga la enseñanza de la historia pueden resultar contraproducentes si se toman dichas síntesis como un paradigma explicativo. Sobre todo, porque estas visiones simplificadas tienden a la larga a fosilizarse en tópicos cuyas hondas raíces acaban siendo difíciles de extirpar. En el caso de la historiografía española concerniente al diecinueve, son dos las visiones monocromáticas que han acabado por injertarse en lo más enraizado de la psique historiográfica: la debilidad/ fracaso/déficit del liberalismo español y la fuerza del clericalismo, entendido como un factor de reacción e inmovilismo para el progreso social. Dos leitmotivs que, pese a las recientes contestaciones, aún planean en la mente tanto de neófitos como miembros del gremio no especializados en el tema.

Con La Santa Sede y los obispos españoles en el Trienio Liberal (1820-1823), el profesor de la Universalidad de Valladolid y miembro de la Real Academia de la Historia Maximiliano Barrio Gozalo trata de enderezar la perspectiva de análisis que ha estigmatizado tanto una cultura política, la liberal, como una élite eclesiástica, el obispado, en una coyuntura de transformación y transición entre «el viejo orden de las cosas» y el orden liberal. El profesor Barrio Gozalo goza de una larga trayectoria en el estudio de la historia eclesiástica en general y en el de los cambios acontecidos en la translatio del 
Antiguo Régimen al Estado liberal en particular. Destacamos su esclarecedora digestión del mundo eclesiástico tanto secular como regular en El clero en la España moderna (2010) y el estudio del patrimonio del clero y el beneficio eclesiástico en El sistema beneficial de la Iglesia Española en el Antiguo Régimen (2011). Estudios recientes que ponen de relieve que la temática que se trata sobre el obispado y el Trienio no es baladí, sino que se cimienta en una larga carrera y en concienzudas investigaciones anteriores, como el artículo «El castigo de los obispos liberales después del Trienio. Pedro González Vallejo, obispo de Mallorca (1819-1825)» (2011), el cual forma parte del volumen que aquí se reseña.

El cuerpo de la obra se divide en cuatro grandes capítulos, junto con un quinto donde se recogen las referencias bibliográficas y el índice onomástico. En las cinco páginas iniciales que forman la introducción, el autor advierte del peligro que conlleva abordar en tan pocas páginas las actitudes y comportamientos de un grupo social tan heterogéneo como fue el obispado. Una dificultad que se atiza -a la vez que se resuelve satisfactoriamente- con la metodología que propone: abordar el problema histórico no como una intrahistoria de los obispos españoles encorsetada en los límites fronterizos del reino peninsular, sino enlazando las dinámicas nacionales, es decir, las opiniones que aparecían en el periódico radical El Universal o las resistencias de algunos prelados a hacer apología de la Constitución, con los puntos de vista que llegaban a la Curia Romana vía a un nuncio como Giustiniani.

4 Precisamente, el primer capítulo, «La curia romana, los obispos y el régimen liberal», parte de las debates romanos acerca de la naturaleza del régimen liberal español. En este juego de puntos de vista cruzados entre la Santa Sede y el Reino de España, destaca el hecho, muchas veces pormenorizado $u$ obviado, que Roma no recelaba de la constitución en lo religioso. Resulta llamativo que el veredicto favorable de la Congregación para los asuntos de España organizada por el papa Pío VII no se hiciera público por motivos políticos. Pese a que Roma no condenó la revolución española y la aceptó con remilgos, la Santa Sede no podía publicitar sus valoraciones en un contexto donde el constitucionalismo ponía en jaque la legitimidad de las monarquías y del sistema estamental. Asimismo, se realza el papel de aquellos hombres de Iglesia comprometidos con el nuevo régimen liberal, como Joaquín Lorenzo Villanueva, cuyas intervenciones en las cortes gaditanas le granjearon las suspicacias de la Santa Sede.

5 En «El gobierno liberal y la reforma de la Iglesia» se ahonda en las medidas y reformas que los distintos gobiernos liberales emprendieron, entre las cuales destacan la libertad de imprenta, la reforma del clero regular, la reforma beneficial y la sacralización del diezmo. El reconocimiento del libre derecho a la difusión escrita de ideas y disquisiciones filosóficas, religiosas y políticas trajo consigo un aluvión de textos satíricos y divulgativos acerca del nuevo escenario que ayudó a ensanchar la brecha entre partidarios de un mayor radicalismo y los refractarios a tales embates. No obstante, no solo la prensa y el teatro se hicieron eco de esa «manía anticlerical» inspirada por escritos como los del racionalista abate Marchena. En muchas ocasiones, la tinta se empleó para justificar los cambios que se tenían que emprender dentro de la Iglesia: los eclesiásticos liberales escribieron a favor de la reforma con el fin de recuperar el espíritu tridentino. La apuesta por una reducción del número de canónigos regulares o la defensa del regalismo eran características sintomáticas de esa nación liberal católica tildada de jansenista sin distinción alguna por parte de la curia romana. 
6 En el tercer capítulo, titulado «El gobierno liberal y los obispos», se explicita la gama de grises que existía entre esos dos grandes bloques que se han presentado como graníticos, encarnados por unos supuestos liberales seglares frente a unos eclesiásticos reaccionarios. En este apartado, Barrio Gozalo traza la problemática que existió entre el proceso de secularización que afectó la elección de clérigos y las resiliencias que presentó la Santa Sede a las cláusulas que ponían en riesgo su autoridad en materia electiva. Tras la nueva aprobación de la constitución de 1812, Roma intentó hacer valer un programa ultramontano donde el rey comunicase el nombre del electo al papa antes del nombramiento. Una agenda que chocó con las medidas regalistas del gobierno español, ya que los obispos eran propuestos por el Consejo de Estado. Asimismo, la Santa Sede quiso suprimir la cláusula concerniente al juramento a la constitución. Un esfuerzo en balde. El nuncio Gravina se dirigió al monarca Fernando VII para que rechazara el artículo argumentando que el concilio de Trento prohibía cualquier innovación en los ritos de administración de sacramentos, pero el gobierno no dio su brazo a torcer.

7 Esta fricción entre el gobierno y Roma prosiguió en las maniobras de ambas partes para proteger a sus allegados. Como relató el cardenal Consalvi, era el papa quien aprobaba a los nuevos purpurados, cuya opinión se basaba en el informe del nuncio, con lo que había un filtro muy difícil de sobrepasar. A su vez, el gobierno hacía todo lo posible para que los cabildos escogiesen vicarios capitulares y nombraran gobernador del obispado a miembros afines al régimen. Las medidas para impermeabilizar el régimen también pasaban por el uso de triquiñuelas varias, como por ejemplo la negativa a conceder el pase regio y la subsecuente captura de bulas para retener la toma de posesión de obispos reaccionarios como Jaime Creus Martí; o la puesta en marcha de un programa de aculturación de las masas mediante la incitación a los altos cargos eclesiásticos de controlar la actitud de sus párrocos, particularmente en Cataluña, donde la situación era delicada por el papel de los curas en la formación de cuadrillas insurgentes.

8 En el último capítulo «El triunfo de la reacción y la represión», el autor presenta cinco retratos ideológico-biográficos de prelados afines o simpatizantes con el nuevo orden de las casos después que se hiciera efectivo en el verano de 1823 la conquista del poder por parte de las fuerzas realistas de los Cien Mil Hijos de San Luis. Entre las trayectorias que se mencionan, destacan los castigos que sufrieron Guillermo Martínez Riaguas, obispo de Astorga, quien tuvo que renunciar a su dignidad tras una furibunda caza por parte del nuncio. Igual fortuna encontraron Pedro González Vallejo, obispo de Mallorca y Antonio Posada, obispo de Cartagena, quienes antes de ser rehabilitados sufrieron el exilio. Menos tortuosas fueron las suertes de Vicente Ramos García, obispo de Segorbe, y Juan García Benito, purpurado de Santiago. Estos dos prelados fueron nombrados por el gobierno liberal y confirmados por Roma, aunque no llegaron a tomar posesión de la diócesis. Sin embargo, la corroboración en el cargo tras la restauración no estuvo exenta de sospechas y recelos por parte de la nunciatura y la curia.

9 En líneas generales, el profesor Barrio Gozalo ofrece una panorámica que quiere erigirse como lienzo general de una coyuntura convulsa como fue el Trienio liberal a partir del análisis de casos concretos. La multitud de archivos consultados, entre los cuales destacan el Archivo Segreto Vaticano, el Archivo degli Affari Ecclesiatici Straordinari y la Biblioteca de la Embajada de España ante la Santa Sede, certifican el rigor de una investigación también atenta a los avances bibliográficos. La madurez con 
la que el autor aborda los nudos históricos, como el conflicto entre el poder secular y eclesiástico mediante la distinción bipartita entre moderados y exaltados por un lado y prelados liberales y reaccionarios por el otro, sirve a la causa de presentar un escenario mental calidoscópico que supere las clasificaciones herméticas que han tendido a presentar la Iglesia como un bastión del Antiguo Régimen. Gracias a esta aproximación se puede inferir que la secularización fue una dinámica también clerical en la medida en que, a raíz de los cambios en la esfera pública, diferentes obispos abogaron por una reestructuración del clero y apostaron por una nueva relación entre el trono y el altar. Así, la defensa de los derechos de regalía encontró en el liberalismo político un camino que permitiera abordar las relaciones con la Santa Sede desde otro ángulo, aunque peligroso por los senderos a los que podía conducir. Una consideración que permitiría recalcar el rol no sólo de los obispos en la salvaguarda y mantenimiento del primer gobierno liberal moderado, sino del papel de la religión y del clero en la formación del liberalismo político español.

\section{AUTORES}

\section{JOAN PUBILL BRUGUÉS}

Universitat Autònoma de Barcelona 